\title{
Analysis of Lymph Node Metastatic Pattern according to the Depth of In-Growth in the Muscularis Propria in T2 Rectal Cancer for Lateral Lymph Node Dissection
}

\author{
Koji Komori $^{a} \quad$ Yukihide Kanemitsu $^{a}$ Seiji Ishiguro ${ }^{a}$ Yasuhiro Shimizu $^{a}$ \\ Tsuyoshi Sano $^{a}$ Tomoyuki Kato $^{\text {b }}$ \\ a Department of Gastroenterological Surgery, Aichi Cancer Center Hospital, and b Department of Surgery, \\ Kamiida Daiichi General Hospital, Nagoya, Japan
}

\section{Key Words}

Rectal cancer · Muscularis propria $\cdot$ Lateral pelvic lymph node $\cdot$ Growth pattern

\begin{abstract}
Background/Aims: The biological behavior of rectal cancers that invade the muscularis propria (pT2) has not been well studied. We retrospectively studied the pattern of lymph node metastases in patients with T2 rectal cancer. Methods: We enrolled 88 patients who had undergone curative resection of T2 colorectal cancer through mesorectal excision and lateral pelvic lymph node dissection; we microscopically estimated the maximum depth of muscularis propria invasion and classified the results into 3 groups representing distinct growth patterns. Results: In cases of pT2 colorectal carcinomas, lateral pelvic lymph node metastases depended on the degree of muscularis propria invasion, and the frequency of metastasis increased with the depth of muscularis propria invasion. Lateral pelvic lymph node metastases were not observed when the depth of muscularis propria invasion was less than half of the thickness of the inner circular layer. Conclusions: These findings suggest that lateral pelvic lymph node metastasis of pT2 colorectal cancer depends on the depth of vertical invasion, which is analogous to the findings in PT1 and pT3 cancers. This information will be useful in se-
\end{abstract}

lect cases in which resection of the lateral pelvic lymph node is required for the treatment of rectal cancer invading the muscularis propria (pT2).

Copyright $\odot 2011$ S. Karger AG, Basel

\section{Introduction}

In Japan, lateral lymph node dissection is generally indicated if the lower margin of the primary cancer is located below the peritoneal reflection or anal canal with invasion into the muscularis propria or deeper [1-4].

However, in rectal cancer cases showing invasion into the muscularis propria ( $\mathrm{pT} 2$ ), the incidence of perirectal lymph node metastases ranges from 24.3 to $29.7 \%$, and the incidence of lateral pelvic lymph node metastases ranges from 5.5 to $8.2 \%$ in patients who undergo lateral pelvic lymph node dissection of rectal cancer $[5,6]$.

The depth of rectal cancer invasion into the muscularis propria varies widely, i.e. from minimal vertical invasion near the submucosal layer (pT1) to very deep vertical invasion near the subserous layer (pT3).

The biological behavior of submucosal cancer (pT1) in the colorectum has been well studied. Under conditions of lymphatic invasion, vascular invasion, poorly differentiated adenocarcinoma and budding, the depth of vertical 
invasion is $\geq 1,000 \mu \mathrm{m}$, and perirectal lymph node metastases are present in about $10 \%$ of these cases [7].

In cases of subserous layer cancer (pT3), the prognosis is influenced by the depth of rectal cancer invasion. Thus, the prognosis worsens as the depth of invasion increases $[8,9]$.

However, the biological behavior of cancers invading the muscularis propria (pT2) has not been well studied.

In this study, we retrospectively estimated the incidence of lateral pelvic lymph node metastases in rectal cancers invading the muscularis propria (pT2).

\section{Patients and Methods}

Between January 1980 and December 2001, 920 patients with rectal cancer underwent curative resection with mesorectal excision and lateral pelvic lymph node dissection at the Department of Gastroenterological Surgery, Aichi Cancer Center Hospital (Nagoya, Japan). Among these, 88 patients who had undergone curative resection of $\mathrm{T} 2$ colorectal cancer were enrolled in this study.

Lateral lymph node dissection was indicated if the lower margin of the primary cancer was located below the peritoneal reflection or anal canal with invasion into the muscularis propria or deeper.

The average patient was 55 years of age (range: $24-76$ ), and the study group included 49 men and 39 women.

Anterior resections were performed on 36 patients (40.9\%), Hartmann's procedure was performed on 1 patient (1.1\%) and abdominoperineal resections were performed on 51 patients $(38.0 \%)$ In total, 61 patients $(69.3 \%)$ were negative and 27 patients $(30.7 \%)$ were positive for lymph node metastasis; furthermore, 19 patients (21.6\%) were positive for mesorectal lymph node metastasis only, 3 patients (3.4\%) were positive for lateral pelvic lymph node metastasis and 5 patients $(5.7 \%)$ were positive for both mesorectal and lateral pelvis lymph node metastasis (table 1).

Lateral pelvic lymph node dissection refers to the complete dissection of the lymph nodes up to the aortic bifurcation, the common iliac lymph nodes, the internal iliac lymph nodes, the external iliac lymph nodes, the middle rectal root lymph nodes and the obturator lymph nodes.

The upper margin of the mesenteric lymph node dissection is the root of the inferior mesenteric artery. The distance from the anal margin should be $\geq 2 \mathrm{~cm}$ when total mesorectal excision is performed.

The resected specimens were fixed with $10 \%$ formalin for several days, and the tumor-containing tissue samples were sliced into 4 -mm sections at the part with the deepest tumor invasion. Histopathological diagnoses were established by hematoxylin and eosin staining using standard procedures without specific immunostaining.

Using a microscope, the maximum depth of muscularis propria invasion was estimated, and the results were used to classify the cases into 3 groups representing different growth patterns, as explained below (fig. 1).

'Type mp slight' indicates that the maximum depth of the muscularis propria invasion is within half of the thickness of the inner circular layer (fig. 2a). 'Type mp moderate' indicates that the maximum depth of the muscularis propria invasion is more than
Table 1. Clinicopathological findings of $88 \mathrm{~T} 2$ rectal cancers

\begin{tabular}{|c|c|}
\hline Age & $55.3 \pm 10.5$ \\
\hline Range & $24-76$ \\
\hline \multicolumn{2}{|l|}{ Gender } \\
\hline Male & $49(55.7)$ \\
\hline Female & $39(44.3)$ \\
\hline \multicolumn{2}{|l|}{ Macroscopic tumor configuration } \\
\hline Protruded type & $11(12.5)$ \\
\hline Ulcerative type & $77(87.5)$ \\
\hline Tumor size, $\mathrm{cm}$ & $4.0 \pm 1.5$ \\
\hline \multicolumn{2}{|l|}{ Histological type } \\
\hline \multicolumn{2}{|l|}{ Well-differentiated and moderately } \\
\hline differentiated types & $82(93.2)$ \\
\hline \multicolumn{2}{|l|}{ Other types (poorly differentiated, } \\
\hline \multicolumn{2}{|l|}{ Lymphatic invasion } \\
\hline Negative & $37(42.0)$ \\
\hline Positive & $51(58.0)$ \\
\hline \multicolumn{2}{|l|}{ Vascular invasion } \\
\hline Negative & $50(56.8)$ \\
\hline Positive & $38(43.2)$ \\
\hline \multicolumn{2}{|l|}{ Operative procedure } \\
\hline Anterior resection & $36(40.9)$ \\
\hline Hartmann & $1(1.1)$ \\
\hline Abdominoperineal resection & $51(58.0)$ \\
\hline \multicolumn{2}{|l|}{ Lymph node metastasis } \\
\hline Negative & $61(69.3)$ \\
\hline Positive & $27(30.7)$ \\
\hline Only mesorectum lymph node positive & $19(21.6)$ \\
\hline Only lateral pelvic lymph node positive & $3(3.4)$ \\
\hline Both mesorectum and lateral pelvic & \\
\hline lymph node positive & $5(5.7)$ \\
\hline
\end{tabular}

Values are means \pm SD or $\mathrm{n}(\%)$, unless otherwise indicated.

half of the thickness of the inner circular layer, with no invasion into the outer longitudinal layer (fig. 2b). 'Type mp massive' indicates that the maximum depth of the muscularis propria invasion is in the outer longitudinal layer (fig. 2c).

From hospital records, we obtained information on a number of variables, including patient age and sex, the operative procedure, macroscopic tumor configuration, and tumor size within the colorectum. On the basis of the data for macroscopic tumor configuration, the tumors were classified as protruded type or ulcerative type. All cases were evaluated by endoscopic ultrasound (EUS), not MRI.

Histological type, lymphatic invasion, venous invasion and the presence or absence of lymph node metastases were investigated using hematoxylin and eosin-stained specimens.

\section{Statistical Analysis}

All data are expressed as means \pm SD. The $\chi^{2}$ test, Fisher's exact probability test and the Mann-Whitney $U$ test were used as appropriate. The multivariate Cox proportional hazards model analysis was then performed. log-rank tests were used to compare survival according to each prognostic factor. A level of $\mathrm{p}<0.05$ was regarded as statistically significant, and CIs were determined at the $95 \%$ level. 
Fig. 1. The greatest depth of the vertical muscularis propria invasion was estimated, and the invasion was classified into 3 growth patterns. The black dashed line indicates the midportion of the inner circular layer of the muscularis propria. 'Type mp slight': the greatest depth of the muscularis propria is within half of the inner circular layer. 'Type mp moderate': the greatest depth of the muscularis propria is beyond half of the inner circular layer, but not in the outer longitudinal layer. 'Type mp massive': the greatest depth of the muscularis propria is the outer longitudinal layer.

Fig. 2. a Hematoxylin and eosin staining for a 'type mp slight' case. The black dots indicate the greatest depth of the tumor and the black dashed line indicates the midportion of the inner circular layer of the muscularis propria. The greatest depth of the muscularis propria is within half of the inner circular layer (the original magnification of the upper figure is $\times 2$ and the original magnification of the lower figure is $\times 40)$.
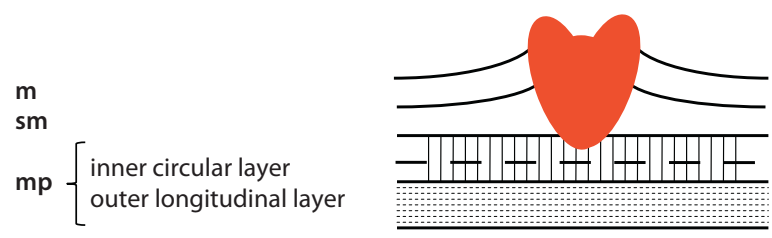

Type mp moderate
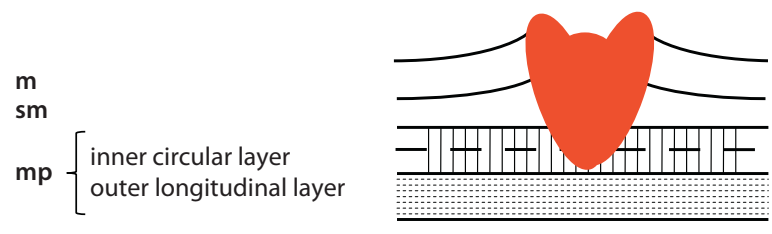

Type mp massive

sm

$\mathbf{m p}\left\{\begin{array}{l}\text { inner circular layer } \\ \text { outer longitudinal layer }\end{array}\right.$

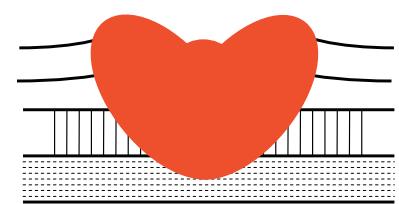

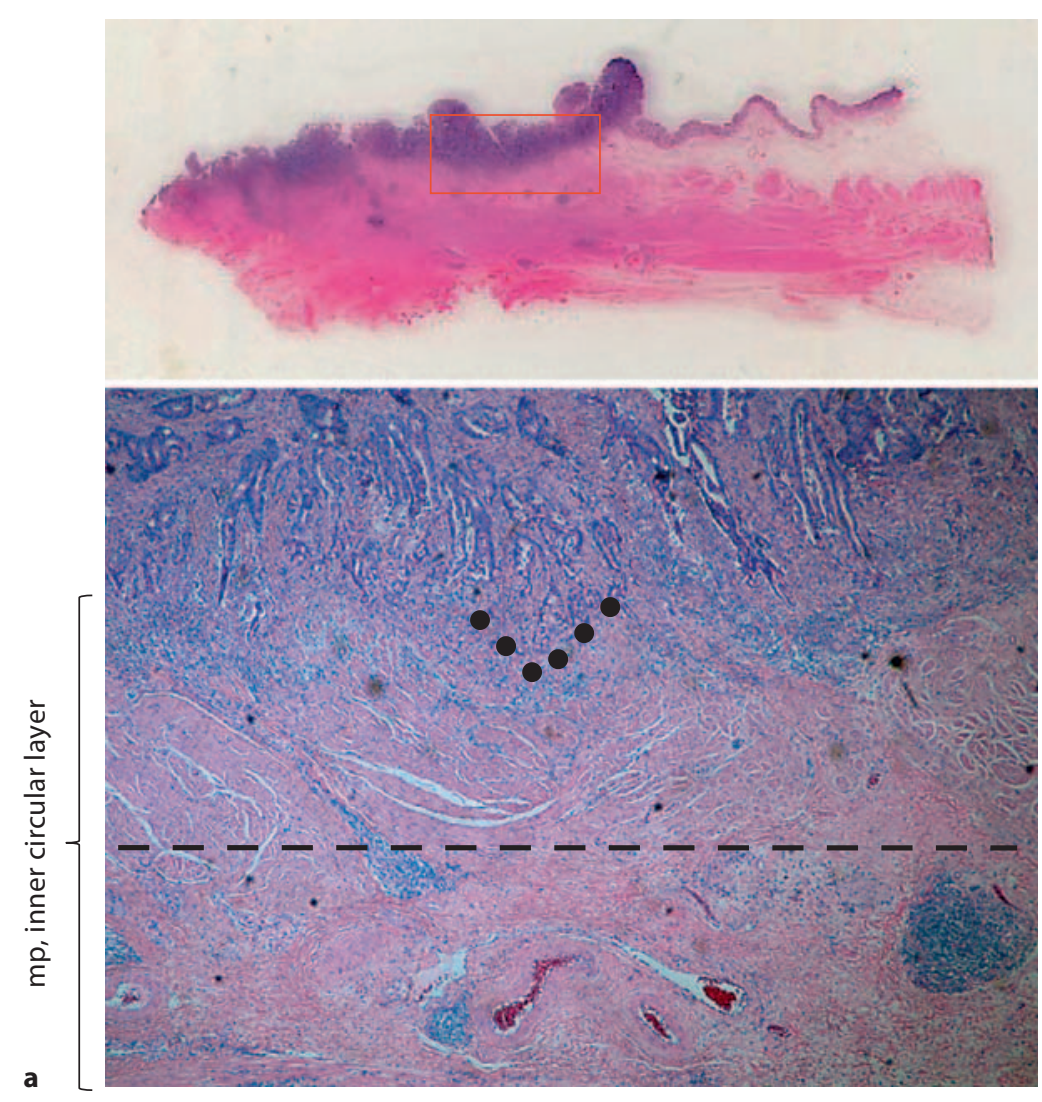


Fig. 2. b Hematoxylin and eosin staining for a 'type mp moderate' case. The black dots indicate the greatest depth of the tumor. The greatest depth of the muscularis propria is beyond half of the inner circular layer but not in the outer longitudinal layer (the original magnification of the upper figure is $\times 2$ and the original magnification of the lower figure is $\times 40$ ). c Hematoxylin and eosin stain of a 'type mp massive' case. The black dots indicate the greatest depth of the tumor. The greatest depth of the muscularis propria is in the outer longitudinal layer (the original magnification of the upper figure is $\times 2$ and the original magnification of the lower figure is $\times 40)$.
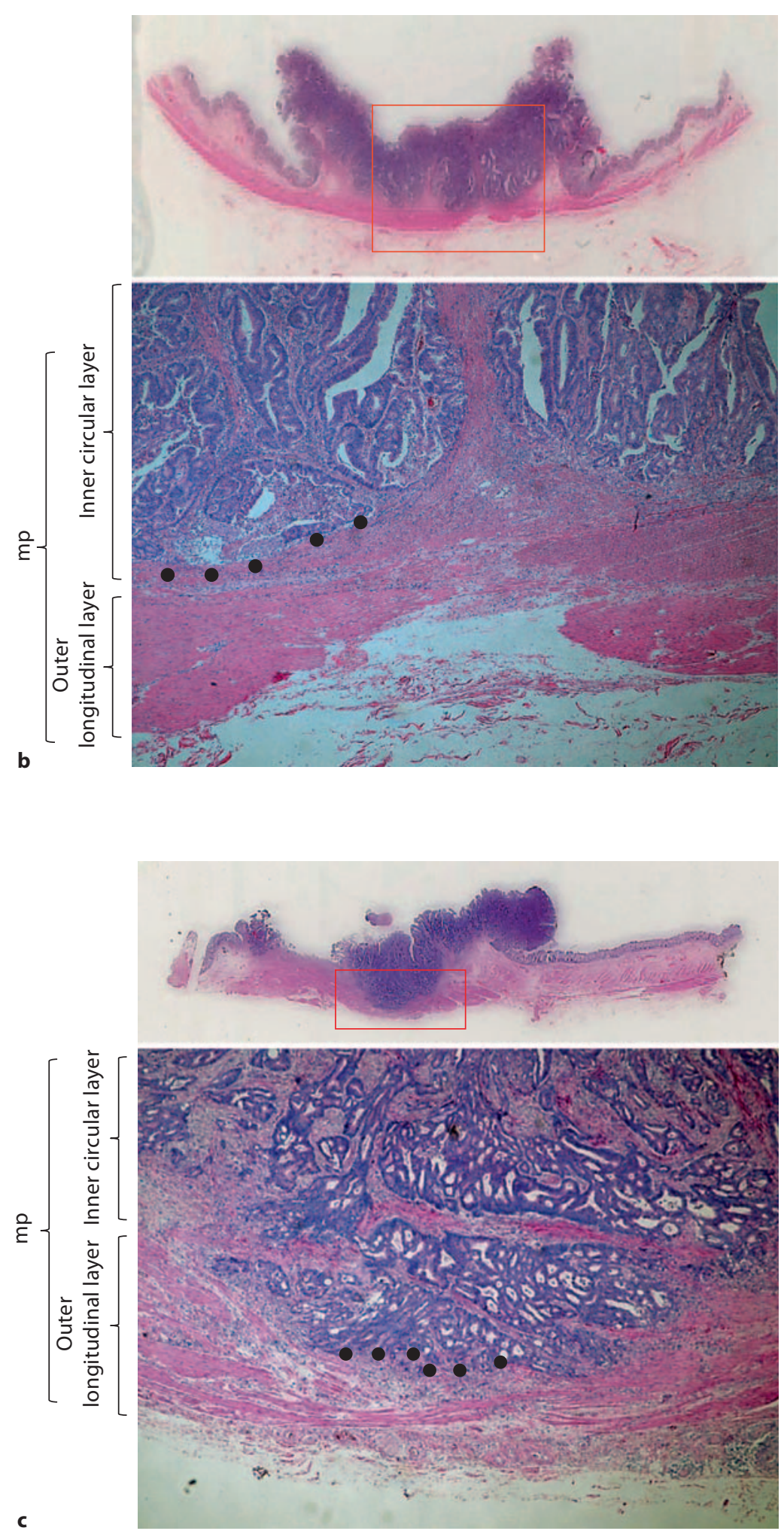

C 
Table 2. Analysis of the correlation between systemic lymph node metastases and clinicopathological findings

\begin{tabular}{|c|c|c|c|c|c|}
\hline & \multirow{2}{*}{$\begin{array}{l}\text { Negative } \\
(\mathrm{n}=61)\end{array}$} & \multirow{2}{*}{$\begin{array}{l}\text { Positive } \\
(\mathrm{n}=27)\end{array}$} & \multirow{2}{*}{$\begin{array}{l}\text { Univariate } \\
\mathrm{p}\end{array}$} & \multicolumn{2}{|c|}{ Multivariate } \\
\hline & & & & $\mathrm{p}$ & HR \\
\hline \multicolumn{6}{|l|}{ Macroscopic tumor configuration } \\
\hline Protruded type & $7(11.5)$ & $4(14.8)$ & \multirow{2}{*}{0.664} & \multirow{2}{*}{0.538} & \multirow{2}{*}{$0.568(0.094-3.430)$} \\
\hline Ulcerative type & $54(88.5)$ & $23(85.2)$ & & & \\
\hline Tumor size, $\mathrm{cm}$ & $4.1 \pm 1.8$ & $3.5 \pm 1.1$ & 0.089 & 0.185 & $0.743(0.479-1.153)$ \\
\hline \multicolumn{6}{|l|}{ Histological type } \\
\hline \multicolumn{6}{|l|}{ Well-differentiated and moderately } \\
\hline $\begin{array}{l}\text { Other types (poorly differentiated, } \\
\text { mucinous and Signet-ring cells) }\end{array}$ & $1(1.6)$ & $5(18.5)$ & 0.004 & 0.119 & $7.331(0.559-89.694)$ \\
\hline \multicolumn{6}{|l|}{ Lymphatic invasion } \\
\hline $\begin{array}{l}\text { Negative } \\
\text { Positive }\end{array}$ & $\begin{array}{l}31(50.8) \\
30(49.2)\end{array}$ & $\begin{array}{r}6(22.2) \\
21(77.8)\end{array}$ & 0.013 & 0.608 & $1.680(0.232-12.186)$ \\
\hline \multicolumn{6}{|l|}{ Vascular invasion } \\
\hline $\begin{array}{l}\text { Negative } \\
\text { Positive }\end{array}$ & $\begin{array}{l}41(67.2) \\
20(32.8)\end{array}$ & $\begin{array}{r}9(33.3) \\
18(66.7)\end{array}$ & 0.003 & 0.390 & $2.536(0.422-15.247)$ \\
\hline \multicolumn{6}{|l|}{ Growth pattern } \\
\hline Type mp slight & $17(27.9)$ & $3(11.1)$ & \multirow{3}{*}{0.010} & \multirow{3}{*}{0.009} & \multirow{3}{*}{$3.119(1.328-7.323)$} \\
\hline Type mp moderate & $29(47.5)$ & $10(37.0)$ & & & \\
\hline Type mp massive & $15(24.6)$ & $14(51.9)$ & & & \\
\hline
\end{tabular}

Values are means \pm SD or $\mathrm{n}(\%)$, unless otherwise indicated.

\section{Results}

The average number of retrieved lymph nodes was 46.3 (range: $10-92$ ), and the average number of metastases was 0.7 (range: $0-15$ ). The average number of retrieved lateral pelvic lymph nodes was 27.4 (range: $1-57$ ), and the average number of metastases was 0.16 (range: $0-5$ ).

Tables 2, 3 and 4 show the results of the univariate and multivariate analyses of the 88 cases with pT 2 colorectal carcinomas.

Table 2 shows the results of the analysis of systemic lymph node metastasis status in the 88 patients. While the 'type mp slight' and 'type mp moderate' growth patterns account for more than half of the cases with negative lymph node metastasis, the 'type mp massive', 'type mp moderate' and 'type mp slight' growth patterns accounted for $51.9,37.0$ and $11.0 \%$, respectively, of the cases with positive lymph node metastasis. Multivariate analysis revealed that the growth patterns showed a significant correlation with the presence of lymph node metastasis $(\mathrm{p}=0.009)$.

Table 3 shows the results of the analysis of the correlation of mesorectal lymph node metastasis with pT2 colorectal carcinoma. Multivariate analysis revealed that the correlation was not statistically significant.
Table 4 shows the results of the analysis of the correlation between lateral pelvic lymph node metastasis and pT2 colorectal carcinomas. Growth patterns and lymphatic invasion were determined to be significant factors influencing this correlation. Of the cases with lateral pelvic lymph node metastasis, $75.0 \%$ were 'type mp massive', $25.0 \%$ were 'type mp moderate' and none were 'type mp slight.' Conversely, of the cases without lateral pelvic lymph node metastasis, $71.2 \%$ were 'type mp slight' or 'type mp moderate', and $28.8 \%$ were 'type mp massive'. Multivariate analysis revealed that the grow th patterns showed a significant correlation with lymph node metastasis $(\mathrm{p}=0.006)$.

Growth patterns are a statistically significant risk factor of lateral pelvic lymph node metastases. In pT 2 colorectal carcinomas, the 'type mp slight' to 'type mp massive' classifications describe the depth of muscularis propria invasion, and the frequency of mesorectal and lateral pelvic lymph node metastases increases gradually.

Figure 3 shows the overall survival rate after surgery and the disease-free survival rate after radical surgery. Although there were no significant differences in the survival rates between patients with different growth patterns, the overall survival rate after surgery and the disease-free survival rate after radical surgery increased in the following order: 'type mp slight' $>$ 'type mp moderate' $>$ 'type mp massive'. 
Table 3. Analysis of the correlation between mesorectal lymph node metastases and clinicopathological findings

\begin{tabular}{|c|c|c|c|c|c|}
\hline & \multirow{2}{*}{$\begin{array}{l}\text { Negative } \\
(\mathrm{n}=64)\end{array}$} & \multirow{2}{*}{$\begin{array}{l}\text { Positive } \\
(\mathrm{n}=24)\end{array}$} & \multirow{2}{*}{$\begin{array}{l}\text { Univariate } \\
\mathrm{p}\end{array}$} & \multicolumn{2}{|c|}{ Multivariate } \\
\hline & & & & $\mathrm{p}$ & $\mathrm{HR}$ \\
\hline \multicolumn{6}{|l|}{ Macroscopic tumor configuration } \\
\hline Protruded type & $7(10.9)$ & $4(16.7)$ & \multirow{2}{*}{0.472} & \multirow{2}{*}{0.402} & \multirow{2}{*}{$0.482(0.087-2.660)$} \\
\hline Ulcerative type & $57(89.1)$ & $20(83.3)$ & & & \\
\hline Tumor size, $\mathrm{cm}$ & $4.1 \pm 1.6$ & $3.6 \pm 1.2$ & 0.207 & 0.316 & $0.803(0.523-1.233)$ \\
\hline \multicolumn{6}{|l|}{ Histological type } \\
\hline \multicolumn{6}{|l|}{ Well-differentiated and } \\
\hline moderately differentiated type & $62(96.9)$ & $20(83.3)$ & \multirow{3}{*}{0.026} & \multirow{3}{*}{0.254} & \multirow{3}{*}{$3.450(0.411-28.959)$} \\
\hline Other types (poorly differentiated, & & & & & \\
\hline mucinous and Signet-ring cells) & $2(3.1)$ & $4(16.7)$ & & & \\
\hline \multicolumn{6}{|l|}{ Lymphatic invasion } \\
\hline Negative & $32(50.0)$ & $5(20.8)$ & \multirow[b]{2}{*}{0.014} & \multirow[b]{2}{*}{0.935} & \multirow{2}{*}{$1.090(0.136-8.724)$} \\
\hline Positive & $32(50.0)$ & $19(79.2)$ & & & \\
\hline \multicolumn{6}{|l|}{ Vascular invasion } \\
\hline Negative & $43(67.2)$ & $7(29.2)$ & \multirow[t]{2}{*}{0.001} & \multirow[t]{2}{*}{0.126} & \multirow[t]{2}{*}{$4.292(0.663-27.764)$} \\
\hline Positive & $21(32.8)$ & $17(70.8)$ & & & \\
\hline \multicolumn{6}{|l|}{ Growth pattern } \\
\hline Type mp slight & $17(26.6)$ & $3(12.5)$ & \multirow{3}{*}{0.074} & \multirow{3}{*}{0.085} & \multirow{3}{*}{$2.007(0.908-4.434)$} \\
\hline Type mp moderate & $29(45.3)$ & $10(41.7)$ & & & \\
\hline Type mp massive & $18(8.1)$ & $11(45.8)$ & & & \\
\hline
\end{tabular}

Values are means \pm SD or $\mathrm{n}(\%)$, unless otherwise indicated.

Table 4. Analysis of the correlation between lateral pelvic lymph node metastases and clinicopathological findings

\begin{tabular}{|c|c|c|c|c|c|}
\hline & \multirow{2}{*}{$\begin{array}{l}\text { Negative } \\
(\mathrm{n}=80)\end{array}$} & \multirow{2}{*}{$\begin{array}{l}\text { Positive } \\
(\mathrm{n}=8)\end{array}$} & \multirow{2}{*}{$\begin{array}{l}\text { Univariate } \\
\mathrm{p}\end{array}$} & \multicolumn{2}{|c|}{ Multivariate } \\
\hline & & & & $\mathrm{p}$ & HR \\
\hline \multicolumn{6}{|l|}{ Macroscopic tumor configuration } \\
\hline Protruded type & $10(12.5)$ & $1(12.5)$ & \multirow{2}{*}{1.000} & \multirow{2}{*}{0.975} & \multirow{2}{*}{$1.058(0.032-35.013)$} \\
\hline Ulcerative type & $70(87.5)$ & $7(87.5)$ & & & \\
\hline Tumor size, $\mathrm{cm}$ & $4.0 \pm 1.5$ & $3.3 \pm 1.2$ & 0.131 & 0.124 & $0.485(0.193-1.218)$ \\
\hline \multicolumn{6}{|l|}{ Histological type } \\
\hline \multicolumn{6}{|l|}{ Well-differentiated and } \\
\hline moderately differentiated type & $76(95.0)$ & $6(75.0)$ & \multirow[b]{2}{*}{0.033} & \multirow[b]{2}{*}{0.812} & \multirow[b]{2}{*}{$1.533(0.045-51.737)$} \\
\hline $\begin{array}{l}\text { Other types (poorly differentiated, } \\
\text { mucinous and Signet-ring cells) }\end{array}$ & $4(5.0)$ & $2(25.0)$ & & & \\
\hline \multicolumn{6}{|l|}{ Lymphatic invasion } \\
\hline $\begin{array}{l}\text { Negative } \\
\text { Positive }\end{array}$ & $\begin{array}{l}36(45.0) \\
44(55.0)\end{array}$ & $\begin{array}{l}1(12.5) \\
7(87.5)\end{array}$ & 0.077 & 0.050 & $36.479(0.998-1,338.062)$ \\
\hline \multicolumn{6}{|l|}{ Vascular invasion } \\
\hline Negative & $47(58.8)$ & $3(37.5)$ & \multirow[t]{2}{*}{0.250} & \multirow{2}{*}{0.250} & \multirow[t]{2}{*}{$0.206(0.014-3.044)$} \\
\hline Positive & $33(41.2)$ & $5(62.5)$ & & & \\
\hline \multicolumn{6}{|l|}{ Growth Pattern } \\
\hline Type mp slight & $20(25.0)$ & $0(0.0)$ & \multirow{3}{*}{0.009} & \multirow{3}{*}{0.006} & \multirow{3}{*}{$14.578(2.194-96.874)$} \\
\hline Type mp moderate & $37(46.3)$ & $2(25.0)$ & & & \\
\hline Type mp massive & $23(28.8)$ & $6(75.0)$ & & & \\
\hline
\end{tabular}

Values are means $\pm \mathrm{SD}$ or $\mathrm{n}(\%)$, unless otherwise indicated. 


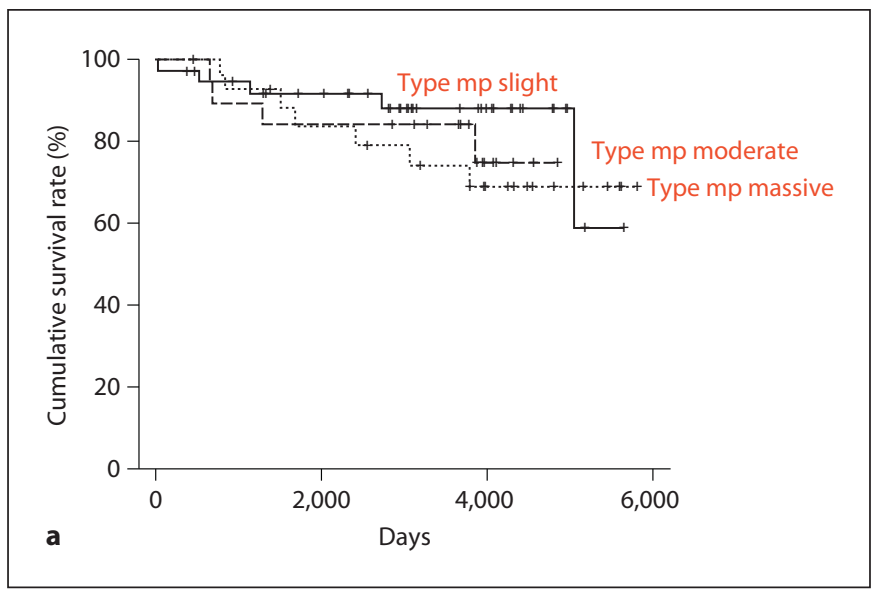

Fig. 3. Prognosis. a Overall survival rate after surgery. 'Type mp slight' vs. 'type mp moderate', $\mathrm{p}=0.395$; 'type mp slight' vs. 'type $\mathrm{mp}$ massive', $\mathrm{p}=0.339$; 'type $\mathrm{mp}$ moderate' vs. 'type mp massive', $\mathrm{p}=0.680$. $\mathbf{b}$ Disease-free survival rate after radical surgery. 'Type

\section{Discussion}

To the best of our knowledge, this is the first report to histopathologically classify $\mathrm{T}$ stages in $\mathrm{pT} 2$ rectal cancer cases in great detail. Pollheimer et al. [10] previously reported on pT 2 rectal cancer cases, but they made only 2 classifications, and the classifications themselves were not detailed. The main finding of this retrospective study is that the lateral pelvic lymph node metastasis of pT2 colorectal cancer depends on the depth of vertical invasion, and this is analogous to the findings obtained for pT1 and pT3 cancers.

Several studies have reported the biological behavior of $\mathrm{pT} 1$ and $\mathrm{pT} 3$ colorectal cancers. In pT1 colorectal cancer, pericolorectal lymph node metastasis is noted when the vertical depth of submucosal invasion exceeds 1,000 $\mu \mathrm{m}$, poorly differentiated adenocarcinoma is the main histological type and is at the deepest invasive portion, and tumor budding is present [7]. Merkel et al. [8] reported that the pT3 type was subdivided into the following groups according to the histological measurements of the maximal tumor invasion beyond the outer border of the muscularis propria: pT3a (up to $5 \mathrm{~mm}$ ) and pT3b (more than $5 \mathrm{~mm}$ ); the prognosis of the former is better than that of the latter. They also reported that of pT3 cancer, cases with a depth of invasion less than $1 \mathrm{~mm}$ had better 5 -year survival rates than those with a depth of invasion greater than $15 \mathrm{~mm}$.

Our study suggests that the deeper the invasion in the muscularis propria, the higher the frequency of perirectal

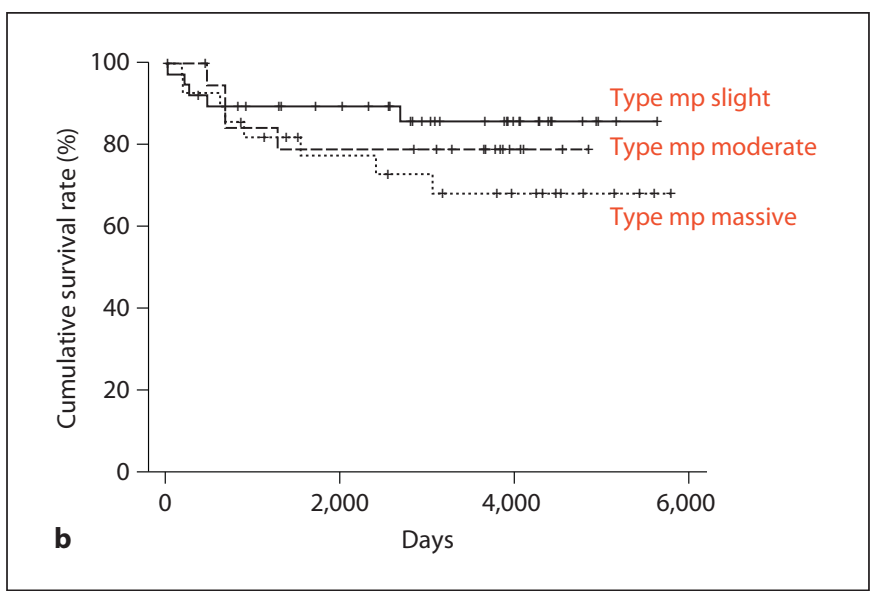

mp slight' vs. 'type mp moderate', $\mathrm{p}=0.563$; 'type mp slight' vs. 'type mp massive', $\mathrm{p}=0.153$; 'type mp moderate' vs. 'type mp massive', $\mathrm{p}=0.490$.

and lateral pelvic lymph node metastases. It also suggests that the biological behavior of pT2 is analogous to that of pT1 and pT3 in that lymph node metastasis is affected by the depth of vertical invasion. This biological behavior is especially similar with respect to lateral pelvic lymph node metastases. In pT1 cases, the vertical depth of the submucosal invasion was $<1,000 \mu \mathrm{m}$, and there was no lymph node metastasis. Similarly, in pT 2 cases, the vertical depth of the submucosal invasions was within half of the thickness of the inner circular layer, and there were no lateral pelvic lymph node metastases.

In Western countries, total mesorectal excision with chemoradiotherapy has now become the standard treatment for advanced rectal cancer. In Japan, however, extended lymphadenectomy with lateral dissection has been aggressively employed for pT2 or more extended rectal cancers located at or below the peritoneal reflection since the late 1970s $[1,3,11]$. There have been no randomized and controlled studies on the usefulness of pelvic sidewall dissections in patients with rectal cancer; therefore, a universal understanding of lateral pelvic lymph node dissection in advanced rectal cancer has not been well established, and the definitive efficacy of pelvic sidewall dissection remains unclear [3].

In other studies, the rates of positive lateral pelvic nodes ranged from 10 to $30 \%$ [3]. In particular, with regard to $\mathrm{T}$ stage, lateral pelvic lymph node metastases occur in 13$14.9 \%$ of rectal cancers localized in the lower rectum below the peritoneal reflection [2]; these metastases also occur in $5.4 \%$ of pT 1 cancers, $8.2 \%$ of pT 2 cancers, $16.5 \%$ of pT 3 
cancers and $37.2 \%$ of T4 cancers [5]. In other studies, lateral pelvic lymph node metastases occurred in $5.5 \%$ of pT2 cases, $16.7 \%$ of pT 3 cases and $23.1 \%$ of T4 cases [6]. According to a previous study $[5,6]$, only a few lateral pelvic lymph node metastases are indicated in pT2 cases. Therefore, a large number of unnecessary extended lymphadenectomies with lateral dissections were carried out in the past. It is essential to establish the selection criteria for an extended lymphadenectomy with lateral dissection.

Our study established that muscularis propria invasion with maximum depth of less than half of the thickness of the inner circular layer in lateral pelvic lymph node metastasis is not an indication. However, if the maximum depth of the muscularis propria extends to the outer longitudinal layer, the frequency of lateral pelvic lymph node metastasis is high. Additionally, the greater the depth of the vertical invasion into the muscularis propria, the higher the frequency of lateral pelvic lymph node metastasis.

Therefore, our retrospective study will shed light on this question of selection criteria. In the near future, if the depth of vertical invasion into the muscularis propria can be accurately measured at the time of preoperative diagnosis, e.g. by EUS, then it will be possible to select cases with a high risk of lateral pelvic lymph node metastasis.
More recently, Puli et al. [12] reported that EUS should be preferably used for the detection of T stage rectal cancers because it has high sensitivity and specificity. The sensitivity of EUS is higher for advanced disease than for early disease. EUS should be strongly considered for $\mathrm{T}$ staging of rectal cancers [12]. Mezzi et al. [13] concluded that EUS and MRI are accurate imaging techniques for staging rectal cancer.

If the preoperative diagnosis can be made on the basis of techniques such as EUS and MRI, pT2 cases could be subdivided for $\mathrm{T}$ staging, i.e. 'type $\mathrm{mp}$ slight', 'type $\mathrm{mp}$ moderate' and 'type mp massive' in rectal cancer, and the findings of our study would make it possible to confirm the positive cases of lateral pelvic lymph node metastases.

\section{Conclusions}

The results of this study suggest that the biological behavior of pT 2 is affected by the depth of vertical invasion. Our findings are useful for the selection of cases in which it is necessary to resect the lateral pelvic lymph nodes for the treatment of rectal cancer invading the muscularis propria (pT2).

\section{References}

1 Moriya Y, Sugihara K, Akasu T, Fujita S: Patterns of recurrence after nerve-sparing surgery for rectal adenocarcinoma with special reference to loco-regional recurrence. Dis Colon Rectum 1995;38:1162-1168.

-2 Mori T, Takahashi K, Yasuno M: Radical resection with autonomic nerve preservation and lymph node dissection techniques in lower rectal cancer surgery and its results: the impact of lateral lymph node dissection. Langenbecks Arch Surg 1998;383:409-415.

- 3 Fujita S, Yamamoto S, Akasu T, Moriya Y: Risk factors of lateral pelvic lymph node metastasis in advanced rectal cancer. Int J Colorectal Dis 2009;24:1085-1090.

-4 Hara M, Hirai T, Nakanishi H, Kanemitsu Y, Komori K, Tatematsu M, Kato T: Isolated tumor cell in lateral lymph node has no influences on the prognosis of rectal cancer patients. Int J Colorectal Dis 2007;22:911-917.

5 Kobayashi H, Mochizuki H, Kato T, Mori T, Kameoka S, Shirouzu K, Sugihara K: Outcomes of surgery alone for lower rectal cancer with and without pelvic sidewall dissection. Dis Colon Rectum 2009;52:567-576.
-6 Moriya Y, Sugihara K, Akasu T, Fujita S: Importance of extended lymphadenectomy with lateral node dissection for advanced lower rectal cancer. World J Surg 1997;21: 728-732.

7 Kitajima K, Fujimori T, Fujii S, Takeda J, Ohkura Y, Kawamata H, Kumamoto T, Ishiguro S, Kato Y, Shimoda T, Iwashita A, Ajioka Y, Watanabe $\mathrm{H}$, Watanabe T, Muto T, Nagasako $\mathrm{K}$ : Correlations between lymph node metastasis and depth of submucosal invasion in submucosal invasive colorectal carcinoma: a Japanese collaborative study. J Gastroenterol 2004;39:534-543.

8 Merkel S, Mansmann U, Siassi M, Papadopoulos T, Hohenberger W, Hermanek P: The prognostic inhomogeneity in $\mathrm{pT} 3$ rectal carcinomas. Int J Colorectal Dis 2001;16:298304.

-9 Maughan NJ, Morris E, Forman D, Quirke P: The validity of the Royal College of Pathologists' colorectal cancer minimum dataset within a population. Br J Cancer 2007;97: 1393-1398.
10 Pollheimer MJ, Kornprat P, Pollheimer VS, Lindtner RA, Schlemmer A, Rehak P, Langner C: Clinical significance of pT sub-classification in surgical pathology of colorectal cancer. Int J Colorectal Dis 2010;25:187196.

11 Moriya Y, Hojo K, Sawada T, Koyama Y: Significance of lateral node dissection for advanced rectal carcinoma at or below the peritoneal reflection. Dis Colon Rectum 1989;32: 307-315.

12 Puli SR, Bechtold ML, Reddy JB, Choudhary A, Antillon MR, Brugge WR: How good is endoscopic ultrasound in differentiating various T stages of rectal cancer? Meta-analysis and systematic review. Ann Surg Oncol 2009;16:254-265.

-13 Mezzi G, Arcidiacono PG, Carrara S, Perri F, Petrone MC, De Cobelli F, Gusmini S, Staudacher C, Del Maschio A, Testoni PA: Endoscopic ultrasound and magnetic resonance imaging for re-staging rectal cancer after radiotherapy. World J Gastroenterol 2009;15: 5563-5567. 